\title{
The impact of childhood food allergy on quality of life of the paediatric population in Jeddah, Saudi Arabia
}

\author{
Yousef H Qari, Abdulaziz A Abu Alnasr, Abdullaziz M Bazaid, Huda A AlHarbi, Nouf \\ ALJahdali, and Loie T Goronfolah
}

King Saud Bin Abdulaziz University for Health Sciences, King Abdulaziz Medical City WR, Jeddah, Saudi Arabia

\section{RESEARCH}

Please cite this paper as: Qari YH, Abu Alnasr AA, Bazaid AM, AlHarbi HA, ALJahdali N, Goronfolah LT. The impact of childhood food allergy on quality of life of the paediatric population in Jeddah, Saudi Arabia. AMJ 2020;13(6):213220.

https://doi.org/10.35841/1836-1935.13.6.213-220

Corresponding Author:

Yousef H Qari

King Saud Bin Abdulaziz University for Health Sciences, King

Abdulaziz Medical City WR, Jeddah, Saudi Arabia

Email: Qari038@ksau-hs.edu.sa

\section{ABSTRACT}

\section{Background}

Food allergy is an allergic reaction to any type of food that differs in its severity and impact on the patient's life as well as on caregivers.

\section{Aims}

To measure the quality of life in the paediatric population with food allergy at National Gourd Health Affairs Jeddah, Saudi Arabia.

\section{Methods}

The food allergy quality of life-parent form was used in this study. The sample size is 75 participants. An Arabic translated and validated version of both questionnaires, with minor modifications were used. Demographic profile, allergy profile, and symptoms profiles were described as frequencies. Cronbach's alpha was calculated for each food allergy quality of life domain. Food allergy quality of life domains were described using the average scores of the summed corresponding variables. A two-way MANOVA was carried out.

\section{Results}

The total score for patients aged $0-3,4-6$, and 7-12 are $2.01,2.56,2.33$, respectively. There was no significant interaction between the independent variables $(p=0.123)$. Age group and gender had no effect on the combined score measuring the quality of life $(p=0.061$, and 0.465 , respectively). The total score for parental concern about food safety is $3.56 \pm 1.15$ (SD) and the total score for child's concern about food safety is $2.81 \pm 1.45$ (SD). Total score for these domains general health perceptions, parental emotional impact, general mental health, and family and child's activities are $1.6 \pm 0.79,2.84 \pm 1.36,3.09 \pm 1.28$, $2.39 \pm 1.27$, respectively.

\section{Conclusion}

There were no significant differences between age groups or gender in the overall score. Only minimal differences were observed in (emotional, social and dietary limitation). We highly recommend further studies in the same field to be able to generalize the results in the Saudi paediatric population.

\section{Key Words}

Paediatric food allergy, quality of life, immunology

\section{What this study adds:}

\section{What is known about this subject?}

Food allergy has a significant impact on various aspects of the paediatric population when compared to their healthy peers.

\section{What new information is offered in this study?}

Food allergy remains to be one of the predictors of poor quality of life in children and their caregivers in the Saudi Population. 
3. What are the implications for research, policy, or practice?

We highly recommend further studies in the same field to be able to generalize the results in the Saudi paediatric population.

\section{Background}

Allergic diseases are a group of chronic immune mediated diseases that are genetically heterogeneous in their nature. ${ }^{1}$ Among these diseases are bronchial asthma, allergic rhinitis, atopic dermatitis, food allergy, and acute urticarial. ${ }^{1}$ The previously mentioned ailments most commonly present among the paediatric population. ${ }^{1}$ Food allergy specifically is an allergic reaction to any type of food that differs in their severity and the directed impact towards the patient's life as well as their caretakers. ${ }^{2}$ Some of these food allergies last for life without having an approved food or drug administration treatment. ${ }^{2}$

The prevalence of food allergy has been increasing in the past few years in developing countries. ${ }^{3}$ According to a study conducted on 1341 patients by the Department of Community Medicine \& Primary Health Care and Asthma Clinic at King Abdulaziz University Hospital in Jeddah, the prevalence of food allergy was 29 per cent among asthmatic patients. ${ }^{4}$ Another study was done in Alnawaria Primary Health Care Center Makkah Al-Mokarramah, the prevalence of food allergy in 182 mothers with their children (age bellow 12) was 22.5 per cent. ${ }^{5}$ The most common reported symptom was itching with percentage of 53.7 per cent, followed by skin rash 48.4 per cent, then skin dryness 26.8 per cent. ${ }^{5}$ Some of those of food allergens are more common than others. ${ }^{4}$ For instance, by the age of four 0 years the prevalence of allergy to peanuts in children is 1.3 per cent. ${ }^{4}$ Meanwhile, peanut allergy has been suggested to develop at even a younger age.

Health-related quality of life (HRQoL) is one of the critical aspects that must be assessed for any patient. ${ }^{6}$ Especially, those with chronic diseases such as food allergy that has no known definitive treatment. ${ }^{6} \mathrm{HRQOL}$ is meant to address the patient's physical and psychosocial wellbeing. ${ }^{6}$ Thus, anxiety and fear from a severe allergic reaction that might be fatal from unintended ingestion of specific food, holds a devastating impact on both children and parents' HRQoL. ${ }^{6}$ There are two methods for HRQoL to be measured in food allergy. $^{7}$ The first method by utilizing generic HRQoL questionnaires which is directed to compare patients of a particular disease with healthy individuals or individuals with other diseases. ${ }^{7}$ However, it lacks the sensitivity to distinguish the influence on HRQoL of the targeted disease from other comorbidities. ${ }^{7}$ On the other hand, Diseasespecific HRQoL questionnaire tend to be more sensitive and more pertinent to the disease of concern. ${ }^{7}$ A systematic review of the literature has reached a conclusion regarding HRQoL in food allergic children, numerous areas of children's HRQoL are significantly affected by the presence of food allergy. ${ }^{7}$ For example, more bodily pain, inferior physical functioning that restricts participation in social activities, and worse mental health have been stressed by children with food allergy. ${ }^{7}$ Moreover, increased school absentees, low self-esteem, less emotional, less psychological wellbeing, and poorer overall health, all of which are proof of worse HRQoL in these patients. ${ }^{7}$ This is more pronounced in children with multiple food allergies or who has a family member with similar complaint. ${ }^{8}$ Likewise, parents with food allergic children have reported less free time, an enormous effect on emotional, social aspects, and restriction in usual activities that involve the whole family. ${ }^{7}$

A limited number of studies are present that relate HRQoL of the affected children and their parents with normal populations. ${ }^{7}$ Also, there is a lack of data favouring a connection between children HRQoL and their parents, many studies have been conducted without adequate sample size to justify the results. ${ }^{7}$ Furthermore, several papers used generic questionnaires which do not distinctly identify the impact of the targeted disease from other commodities. ${ }^{7}$

Therefore, this study was formulated to measure the quality of life in the paediatric population with food allergy in Saudi Arabia. In addition, to participate in the contribution to the literature of patients with food allergy in Saudi Arabia and to increase the awareness regarding this chronic disease. Finally, based on our knowledge, there are no studies in Saudi Arabia that focus on measuring the quality of life in this group of society.

\section{Method}

The study was conducted in National Guard Hospital Jeddah. The study enrolled pediatric patients aged 0-12 years with a history of clinical diagnosis of food allergy and food-specific immunoglobulin E (IgE) testing to confirm the diagnosis according to results and data from electronic medical records. The sample was obtained through nonprobability consecutive sampling method. The patients who were involved in the study had to be registered in the Best care system, electronic medical record, from its start in May 2016. On the other hand, the study excluded patients above 12 years of age, or patients with no clinical diagnosis or negative (IgE) testing. Patients who are not qualified to 
receive treatment at the National Guard Hospital. The sample size is 75 participants. Calculated based on the number of patients with food allergy (192) from the start of best care system May 2016 until the end of August 2018 with 95 per cent confidence interval and 5 per cent margin of error.

The food allergy quality of life-parent form FAQLQ-PF is a questionnaire that measures the quality of life of children with food allergy from their parents' prospective. The original questionnaire has 13,26 , and 30 items for the $0-3$, 4-6, and 7-12-year age groups, respectively. The questionnaire is divided into three major domains emotional impact, food-related anxiety, and social \& dietary limitations. In addition, the study also utilized the food allergy independent measure (FAIM) questionnaire which is composed of four questions and considered one of the disease specific questionnaires that reflect the probability of accidental exposure and how severe the disease is. The questionnaire is scored based on six-point Likert scale that evaluate expectation of outcome of parents with children who suffer from food allergy. An Arabic translated version of both questionnaires, with minor modifications were used. The version was adopted from a validated questionnaire which is made available for private research. An expert in the field of the study revised the questionnaire and feedback was obtained regarding the translation. Piloting was implemented in a sample of 10 participants and editing was done for both questionnaires to be more culturally and linguistically appropriate. All questionnaires were filled through both in person interviews and mostly through phone calls, phone numbers were made available from the best care system. The study protocol was approved by the institutional review board of King Abdullah International Medical Research Center.

Demographic profile, allergy profile, and symptoms profiles were described as frequencies. Cronbach's alpha was calculated for each food allergy quality of life domain. Food allergy quality of life domains were described using the average scores of the summed corresponding variables. A two-way MANOVA was carried out. Gender acted as the mediator variable, and age group acted as the focal variable. The dependent variables were the averages of the summed following domains: emotional impact, food-related anxiety, and social and dietary limitation. All of which were done using SPSS version 26 (IBM Corp., Armonk, N.Y., USA). A $p$-value was set to be significant at $\leq 0.05$.

\section{Results}

A total of 75 participants were included in the study ranged from 0-12 years. 27 participants were in the age group from 0-3 years, 23 were from 4-6 years, and the last 25 participants were from 7-12 years. 41 (54.7 per cent) of the involved sample were males and 34 (45.3 per cent) were females. The remaining characteristics and clinical features along with the specialty of the physicians who made the diagnosis of food allergy are stated in Table 1 . Table 2 demonstrates the presence and timing of anaphylaxis. Also, it mentions the number of patients who were given epinephrine pens and how prescribing it is reflected on patients' and caregivers' emotions. Table 3 displays score distribution and internal consistency of FAQLQ-PF for each age group in relation to the previously mentioned three major domains. The total score for patients aged 0-3 which includes both genders was 2.01 and for 4-6 years patients total score was 2.56 for age group 7-12 the total score was 2.33. Finally, a two-way MANOVA was carried to access the effect of gender and age group on scores of emotional impact, food-related anxiety, and social \& dietary limitations. The combined score of emotional impact, foodrelated anxiety and social \& dietary limitations was used to access the quality of life of patients with food allergy. There was no significant interaction between the independent variables $(p=0.123)$. Age group and gender had no effect on the combined score measuring the quality of life $(p=0.061$, and 0.465 , respectively). FAIM items total score and internal consistency are measured in Table 4 which is subdivided into two main dimensions parental and child's concern about food safety. The total score for parental concern about food safety is $3.56 \pm 1.15$ (SD) and the total score for child concern about food safety is $2.81 \pm 1.45$ (SD). However, both showed unacceptable to poor Cronbach's alpha. Table 5 states other questions that are organized into several domains reported by the participants. The domains are general health perceptions, parental emotional impact, general mental health, and family and child's activities. Total score for these domains is $1.6 \pm 0.79,2.84 \pm 1.36,3.09 \pm 1.28$, $2.39 \pm 1.27$, respectively. Furthermore, Internal Consistency is $0.66,0.89,0.91,0.89$, respectively.

An item was added and rated on the same scale that was used for the first FAQLQ-PF questionnaire to measure the presence and severity of bullying in our sample because of food allergy, my child has suffered from physical or psychological trauma inside or outside the school' the score was $0.94 \pm 1.67$ (SD).

\section{Discussion}

The study demographics differ when compared to other 
papers that were conducted in other parts of the world. In a research that was held in Texas, United States of America, which discussed the QoL in paediatric patients with food allergy, the study distributed two forms of the questionnaire for their sample, a parent form and teenager form of the FAQLQ-PF. ${ }^{9}$ The percentage of gender distribution for the parent form sample is (55.4 per cent) for male and (44.6 per cent) for the female which is similar to the percentage of this study. ${ }^{9}$ In this study, age distribution was almost equal among all age groups. The most common food that children in the Texas study were allergic to is peanut followed by nuts. ${ }^{9}$ However, in this study the most common food is milk followed by egg. The most severe allergic reaction was observed with milk, the most prevalent system that was affected during an allergic reaction is skin. Moreover, in Texas study the most commonly affected system was skin as well. ${ }^{9}$ In Table 2 the history of anaphylaxis was negative in slightly more than half of participants the rest of participants had a positive history of anaphylactic shock that is ranged from very recent up to more than two years. On the other hand, Texas study had (47.3 per cent) participants with previous history of anaphylaxis. ${ }^{9}$

The percentage of children receiving epinephrine pen in this study was (72 per cent) when compared to Texas paper which was (93.3 per cent). ${ }^{9}$ Noteworthy, 10 children with anaphylaxis history in this study did not receive epinephrine pens. This might be due to global shortage, up to the time of conducting this study, in epinephrine pen that is attributed to a manufacturing delay. ${ }^{10,11}$ This was noted while filling the questionnaires as some participants reported not receiving new epinephrine pens. (81.3 per cent) of caregivers were reassured by the provision of epinephrine pen and (46.7 per cent) of children were reassured as well. Nevertheless, (43.7 per cent) of caregivers were anxious by receiving it, and ( 6.7 per cent) of the children were also anxious. In Texas paper (90.7 per cent) and (62.7 per cent) of caregivers and children were reassured, respectively. In contrast, (36.7 per cent) and (22 per cent) of caregivers and children were anxious, respectively. $^{9}$

In our study it has been observed that the score of emotional impact for both males and females is increased with increasing age. Additionally, the score of social and dietary limitation for both genders observed to be higher among older children compared to other age groups. This finding is similar to pervious study, which reported that both the median emotional impact, social, and dietary limitation score was significantly higher in teens compared to children $(P=0.019)$ and $(P=0.002)$, respectively. ${ }^{9}$ However, in this study the overall score of quality of life was similar between age groups and gender with no significant difference $(\mathrm{P}=0.061)$ and $(\mathrm{P}=0.465)$, respectively. In contrast to other studies who reported higher total score of FAQLQ which indicated worse quality of life in teenagers. ${ }^{9,12,13}$ This might be attributed to the fact that parent report better quality of life when they are asked on behalf of their children. ${ }^{14}$

The statistical results shown in Table 4 showed that children may experience severe consequences due to consuming food that they are allergic to by mistake, which would worsen their quality of life. However, unacceptable Cronbach's alpha levels demonstrate the need for further investigations to the reasons of inconsistency. Initial possible cause is the length of the questionnaire which might had the respondents to rush through the last part of the questions. Additionally, in contrast to Texas study where part of respondents answered the questionnaire by themselves, our study relied on parents to fill the questionnaire. For other reported domains, the highest score was observed in general mental health followed by parental emotional impact. Low general mental health was strongly associated with poorer overall FAQLQ scores in children who were involved in Texas study. ${ }^{9}$

Regarding the item that highlights the presence and severity of bullying, the result indicates a very low level of participants who were bullied. This might be underreported as other researches state that third of food allergic patients are bullied. ${ }^{15}$ In Saudi Arabia a multiregional study that involved more than 10,000 participants reports that (39 per cent) of them have been bullied. This might be attributed to the reason that the used forms are filled by the caregivers who may not be aware of their children's life in school or outside home.

\section{Conclusion}

Food allergy has a significant impact on children and their families, affecting quality of life in multiple aspects. In this study, there were no significant differences between age groups or gender in the overall score. Only minimal differences were observed in (emotional, social and dietary limitation). FAQLQ-PF has a tremendous negative impact in accurately measuring the QoL of paediatric patients with food allergy. This was clearly stated in the available literature. Moreover, Questionnaires are subject to recall bias which could have influenced this study as well. The study was held in merely one center in the city of Jeddah, Saudi Arabia. As a result, the study population might not 
represent all paediatric patients with food allergy in this region. However, this paper stands, as far as we know, as the only study in the region that sheds the light on this subject. It also pioneers as the first study providing an Arabic version of the validated questionnaire. However, we highly recommend further studies in the same field to be able to generalize the results in the Saudi paediatric population. Finally, Patients' education and awareness promotion should be taken into consideration when managing patients with food allergy to provide optimal care.

\section{References}

1. Hendaus MA, Jomha FA, Ehlayel M. Allergic diseases among children: nutritional prevention and intervention. Ther Clin Risk Manag. 2016;12:361-72. doi: 10.2147/TCRM.S98100.

2. Lieberman J, Sicherer S. Quality of life in food allergy. Curr Opin Allergy Clin mmunol. 2011;11(3):236-42. doi: 10.1097/ACl.0b013e3283464cfo.

3. Savage J, Johns C. Food allergy: Epidemiology and natural history. Immunol Allergy Clin North Am. 2015;35(1):45-59. doi: 10.1016/j.iac.2014.09.004.

4. Aba-Alkhail BA, El-Gamal FM. Prevalence of food allergy in asthmatic patients. Saudi Med J. 2018;21:81-7. PMID: 11533756

5. Damanhori NK. Food allergy among children under 12 years of mothers attending a well baby clinic at an ALEskan primary health care center, Makkah AlMokarramah, 2013. Int J Med Sci Public Health. 2015;4:700-8. doi: 10.5455/ijmsph.2015.18022015144

6. DunnGalvin A, Chang WC, Laubach S, et al. Profiling families enrolled in food allergy immunotherapy studies. Pediatrics. 2009;124:e503-9. doi: 10.1542/peds.20083642.

7. Morou Z, Tatsioni A, Dimoliatis ID, et al. Health-related quality of life in children with food allergy and their parents: a systematic review of the literature. - PubMed - NCBI [Internet]. Ncbi.nIm.nih.gov. 2018 [cited 4 August 2018]. Available from: https://www.ncbi.nlm.nih.gov/pubmed/25668890.

8. Antolín-Amérigo $D$, Manso L, Caminati M, et al. Quality of life in patients with food allergy. Clin Mol Allergy. 2016;14(1). https://doi.org/10.1186/s12948-016-0041-4.

9. Miller J, Blackman A, Wang $H$, et al. Quality of life in food allergic children. Annals of Allergy, Asthma \& Immunology. 2020;124(4):379-84. doi: https://doi.org/10.1016/j.anai.2019.12.021

10. Huggins C. As EpiPen shortage continues, clinicians and patients turn to alternatives. Pharmacy Today. 2019;25(10):19.
11. FDA alerts patients and health care professionals of EpiPen [Internet]. U.S. Food and Drug Administration. 2020 [cited 23 May 2020]. Available from: https://www.fda.gov/drugs/drug-safety-andavailability/fda-alerts-patients-and-health-careprofessionals-epipen-auto-injector-errors-related-device

12. Wassenberg J, Cochard M, Dunngalvin A, et al. Parent perceived quality of life is age dependent in children with food allergy. Pediatr Allergy Immunol. 2012;23:412-9. doi:10.1111/j.1399-3038.2012.01310.x

13. Thörnqvist $V$, Middelveld $R$, Wai $H M$, et al. Healthrelated quality of life worsens by school age amongst children with food allergy. Clin Transl Allergy. 2019;9:10. doi: 10.1186/s13601-019-0244-0

14. van der Velde J, Flokstra-de Blok B, DunnGalvin A, et al. Parents report better health-related quality of life for their food-allergic children than children themselves. Clin Exp Allergy. 2011;41(10):1431-9. doi: 10.1111/j.1365-2222.2011.03753.x

15. Almuneef M, ElChoueiry N, Saleheen $H$, et al. The impact of adverse childhood experiences on social determinants among Saudi adults. J Public Health. 2017;40(3):219-27. doi: $10.1093 /$ pubmed/fdx177

\section{ACKNOWLEDGEMENTS}

The authors would like to thank Dr. Amr Albanna, Dr. Muhammad Anwar Khan, and King Abdullah International Medical Research Center for their ethical approval. Finally, we thank the EuroPrevall project for making this questionnaire available for research purposes.

\section{PEER REVIEW}

Not commissioned. Externally peer reviewed.

\section{CONFLICTS OF INTEREST}

The authors declare that they have no competing interests.

\section{FUNDING}

This research did not receive any specific grant from any funding agencies of the public, commercial, or non-profit sector.

\section{ETHICS COMMITTEE APPROVAL}

King Abdullah International Medical Research Center, institutional review board.

Study number: SP18/497/J

Ref. No. RYD-18-417780-200262 
Table 1: Descriptive characteristics of the participants

\begin{tabular}{|c|c|}
\hline \multicolumn{2}{|c|}{ Participants n=75 (\%) } \\
\hline \multicolumn{2}{|c|}{ Demographic profile } \\
\hline \multicolumn{2}{|l|}{ Parental sex } \\
\hline Male & $34(45.3)$ \\
\hline Female & $41(54.7)$ \\
\hline \multicolumn{2}{|l|}{ Child sex } \\
\hline Male & $41(54.7)$ \\
\hline Female & $34(45.3)$ \\
\hline \multicolumn{2}{|l|}{ Child age } \\
\hline $0-3$ years old & $27(36)$ \\
\hline $4-6$ years old & $23(30.7)$ \\
\hline $7-12$ years old & $25(33.3)$ \\
\hline \multicolumn{2}{|l|}{ Allergy profile } \\
\hline \multicolumn{2}{|c|}{ Which food is your child allergic to? ${ }^{*}$} \\
\hline Peanut & $22(29.3)$ \\
\hline Nut & $30(40)$ \\
\hline Milk & $44(58.7)$ \\
\hline Egg & $38(50.7)$ \\
\hline Wheat & $18(24)$ \\
\hline Soya & $10(13.3)$ \\
\hline Sesame & $33(44)$ \\
\hline Fish & $5(6.7)$ \\
\hline Shellfish & $4(5.3)$ \\
\hline Fruits & $18(24)$ \\
\hline Vegetables & $8(9.3)$ \\
\hline Other** & $15(20)$ \\
\hline \multicolumn{2}{|c|}{ Number of foods avoided } \\
\hline $0-2$ & $28(37.3)$ \\
\hline $3-6$ & $33(44)$ \\
\hline $7-10$ & $4(5.3)$ \\
\hline $10+$ & 10 (13.3) \\
\hline
\end{tabular}

Most commonly reported foods that cause severe reaction when ingested.

\begin{tabular}{|c|c|}
\hline Milk & $13(17.3)$ \\
\hline Egg & $11(14.7)$ \\
\hline Nut & $10(13.3)$ \\
\hline Sesame & $10(13.3)$ \\
\hline \multicolumn{2}{|l|}{ Type of symptoms* } \\
\hline Cardiovascular ${ }^{\S}$ & $7(9.3)$ \\
\hline Respiratory tract ${ }^{\pi}$ & $26(34.7)$ \\
\hline Gastrointestinal tract $^{*}$ & $17(22.7)$ \\
\hline $\operatorname{Skin}^{f}$ & $50(66.7)$ \\
\hline Other ${ }^{€}$ & $23(30.7)$ \\
\hline
\end{tabular}

\begin{tabular}{|c|c|}
\hline G.P. & $8(10.7)$ \\
\hline Consultant Allergist & $64(85.3)$ \\
\hline Consultant Paediatrician & $10(13.3)$ \\
\hline Dermatologist & $6(8)$ \\
\hline Dietician & $5(6.7)$ \\
\hline Alternative Practitioner & $2(2.7)$ \\
\hline \multicolumn{2}{|c|}{$\begin{array}{l}\text { Participants might pick multiple items } \\
\text { " Cheese, legume, zaatar, Chocolate, honey, chicken } \\
\text { Dizziness, palpitations, loss of vision, inability to stand, light } \\
\text { headedness, collapse, loss of consciousness } \\
\text { " Tightening throat, difficulty swallowing, hoarseness, difficulty } \\
\text { breathing, shortness of breath, wheezing, cough, sneeze } \\
{ }^{*} \text { Nausea, stomach cramps, vomiting, diarrhoea } \\
\text { £ Itchy skin, red rash, swelling of the skin, hives, worsening } \\
\text { eczema } \\
{ }^{€} \text { Swollen tongue or lips, symptoms of the nose or eyes }\end{array}$} \\
\hline
\end{tabular}

Table 2: History of anaphylaxis and epinephrine pen related questions

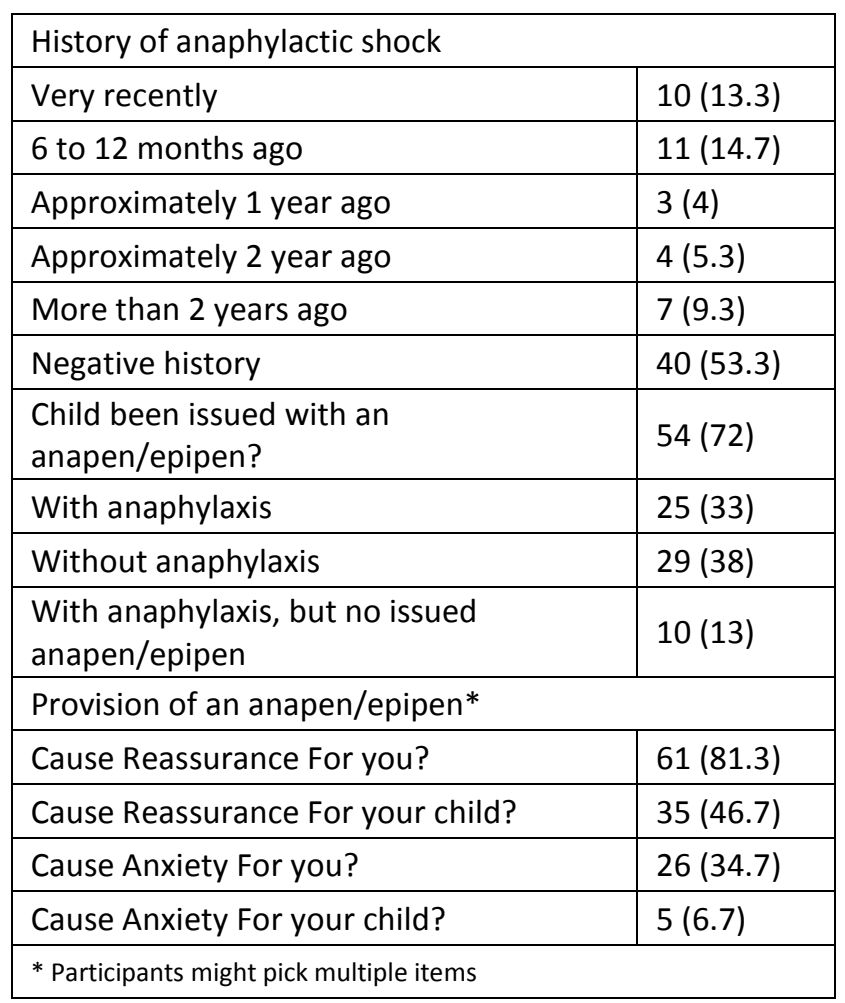


Table 3: Score distribution of the corresponding age and gender and their internal consistency values of FAQLQ-PF questionnaire

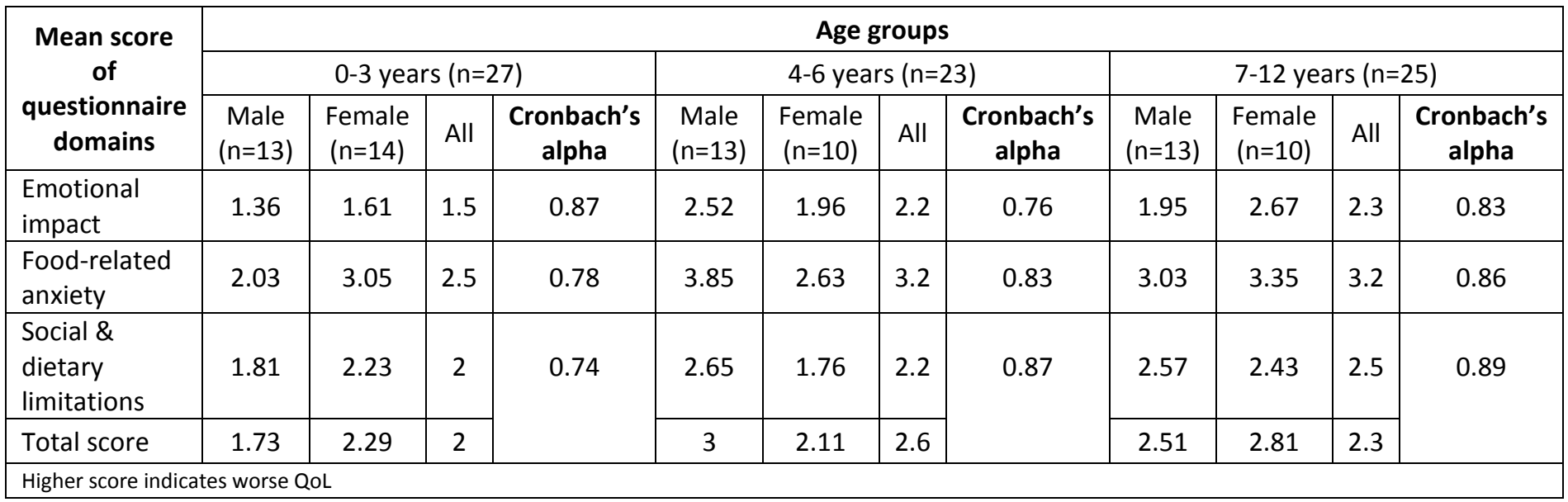

Table 4: FAIM Items total score mean, standard deviation, and their Internal Consistency values

\begin{tabular}{|c|c|c|}
\hline Parental concern about food safety & $\begin{array}{l}\text { Total score } \\
\text { Mean (SD) }\end{array}$ & $\begin{array}{l}\text { Cronbach's } \\
\text { alpha }\end{array}$ \\
\hline $\begin{array}{l}\text { What chance do you think your child has of accidentally ingesting the food to which they } \\
\text { are allergic? }\end{array}$ & \multirow{4}{*}{$3.56 \pm 1.15$} & \multirow{4}{*}{0.46} \\
\hline $\begin{array}{l}\text { What chance do you think your child has of having a severe reaction if food is accidentally } \\
\text { ingested? }\end{array}$ & & \\
\hline $\begin{array}{l}\text { What chance do you think your child has of dying from his/her food allergy following } \\
\text { ingestion in the future? }\end{array}$ & & \\
\hline $\begin{array}{l}\text { What chance do you think your child has of effectively treating him/ herself or receiving } \\
\text { effective treatment from others (including Epipen administration)? }\end{array}$ & & \\
\hline \multicolumn{3}{|l|}{ Child's concern about food safety } \\
\hline $\begin{array}{l}\text { What chance does your child think he/she has of accidentally ingesting the food to which } \\
\text { they are allergic? }\end{array}$ & \multirow{4}{*}{$2.81 \pm 1.45$} & \multirow{4}{*}{0.64} \\
\hline $\begin{array}{l}\text { What chance does your child think he/she has of having a severe reaction if food is } \\
\text { accidentally ingested? }\end{array}$ & & \\
\hline $\begin{array}{l}\text { What chance does your child think he/she has of dying from his/her food allergy following } \\
\text { ingestion in the future? }\end{array}$ & & \\
\hline $\begin{array}{l}\text { What chance does your child think he/she has of effectively treating him/ herself or } \\
\text { receiving effective treatment from others (including Epipen administration)? }\end{array}$ & & \\
\hline
\end{tabular}

Table 5: Other domains' total score mean, standard deviation, and their internal consistency values

\begin{tabular}{|c|c|c|c|}
\hline \multicolumn{2}{|c|}{$\begin{array}{l}\text { Other domains' total score mean, standard deviation, and their internal consistency } \\
\text { values }\end{array}$} & $\begin{array}{c}\text { Total } \\
\text { score } \\
\text { Mean (SD) }\end{array}$ & $\begin{array}{l}\text { Cronbach's } \\
\text { alpha }\end{array}$ \\
\hline \multirow{3}{*}{$\begin{array}{l}\text { General health perceptions } \\
\text { (GHP) }\end{array}$} & How would you describe... & \multirow[t]{3}{*}{$1.6 \pm 0.79$} & \multirow[t]{3}{*}{0.66} \\
\hline & ...Your general health? & & \\
\hline & ...Your child's general health? & & \\
\hline \multirow[t]{2}{*}{ Parental emotional Impact (PEI) } & $\begin{array}{l}\text { Because of food allergy, how much worry/concern } \\
\text { does )... }\end{array}$ & \multirow[t]{2}{*}{$2.84 \pm 1.36$} & \multirow[t]{2}{*}{0.89} \\
\hline & ...your child's physical health cause you? & & \\
\hline
\end{tabular}




\begin{tabular}{|c|c|c|c|}
\hline & ...your child's emotional wellbeing cause you? & & \\
\hline \multirow[t]{3}{*}{ General mental health (GMH) } & $\begin{array}{l}\text { What level of stress does your child's food allergy } \\
\text { cause... }\end{array}$ & \multirow[t]{3}{*}{$3.09 \pm 1.28$} & \multirow[t]{3}{*}{0.91} \\
\hline & ...You? & & \\
\hline & ...Your Partner? & & \\
\hline \multirow[t]{3}{*}{ Family and child's activities (FA) } & How much has food allergy limited the type of... & \multirow[t]{3}{*}{$2.39 \pm 1.27$} & \multirow[t]{3}{*}{0.89} \\
\hline & ...activities you can do as a family? & & \\
\hline & ...activities your child can take part in? & & \\
\hline
\end{tabular}

